\title{
DIÁLOGOS DO HABITUS PROFESSORAL E ORIENTAL NAS MEMÓRIAS DE PROFESSORAS APOSENTADAS DE ORIGEM JAPONESA*
}

\author{
Miriam Mity Nishimoto \\ Universidade Anhanguera, Campo Grande, MS, Brasil \\ Jacira Helena do Valle Pereira \\ Universidade Federal de Mato Grosso do Sul, Campo Grande, MS, Brasil
}

\begin{abstract}
Resumo: Nesse trabalho examinamos memórias de professoras aposentadas de origem japonesa, para compreender o papel que a cultura do grupo de origem étnica teve na trajetória de formação e ação docente, instituindo maneiras de ser e estar na profissão habitus professoral. Metodologicamente, utilizamos as técnicas de história de vida para coleta dos relatos e análise de conteúdo, com o auxílio tecnológico do software NVivo8 para a organização dos dados. As análises foram realizadas à luz da teoria de Pierre Bourdieu e interlocutores, a qual nos possibilitou constatar que, nas trajetórias de vida, as professoras incorporaram valores da cultura de origem, isto é, um habitus oriental que perdurou e colaborou com a estruturação de um habitus professoral.

Palavras-Chave: Memória. Professoras aposentadas. Habitus oriental. Habitus professoral.
\end{abstract}

\section{INTRODUÇÃO}

Este estudo é um recorte de uma investigação ${ }^{1}$ que consistiu na análise de memórias de quatro professoras aposentadas de origem japonesa, que lecionaram entre os anos de 1965 e 2006, na escola de cunho étnico Visconde de Cairu (1918), em Campo Grande, MS.

Para esta discussão, perscrutamos as memórias das professoras para compreender o papel que a cultura de origem étnica jogou nas trajetórias

\footnotetext{
* Artigo recebido em 1/6/2012 e aprovado em 5/2/2013.
} 
de formação e ação docente, isto é, para reconhecer as marcas da herança cultural que foram incorporadas e colaboraram nas maneiras de ser e de estar na profissão, traduzidas pela noção de habitus professoral (SILVA, 2003; 2005).

No cenário que envolve o presente estudo, destaca-se a presença dos japoneses no local e as estratégias do grupo na criação da escola Visconde de Cairu. De fato, o referido espaço simbolizou a materialização dos ideais dos japoneses de proporcionar aos descendentes o acesso ao saber institucionalizado uma vez que isso não era facultado à população local, tampouco aos filhos de imigrantes que se concentravam no respectivo município, nos idos de 1918.

A criação da escola foi favorecida pela própria necessidade do grupo em utilizar estratégias no campo educacional para favorecer sua inserção e ascensão na sociedade local. Além disso, o forte desejo coletivo de oferecer uma escolarização dentro dos moldes da cultura japonesa sempre contribuiu como um reforço a mais para a inculcação de valores culturais nas gerações de japoneses.

Inicialmente, a escola foi pensada por japoneses e para os japoneses, bem como a composição do quadro docente, simbolizando a importância de atribuir ao profissional a responsabilidade de transmitir aos filhos de imigrantes os ideais coletivos. Significativa a oportunidade de transformar as práticas profissionais de acordo com a necessidade do grupo, bem como a intenção de oferecer suporte às novas gerações para o enfrentamento de diversas situações na sociedade de acolhimento.

$\mathrm{Na}$ trajetória da escola, constatamos que o professor, como agente educacional disposto a agir em sintonia com o grupo, estruturou e reestruturou estratégias de conservação do campo educacional por meio da ação docente. Por esse motivo, consideramos relevante ouvir as vozes daqueles que foram testemunhas e agentes envolvidos no processo educativo de várias gerações de japoneses.

Como durante longo período, as professoras formaram agentes e se instituíram na docência, desenvolvemos uma análise da trajetória de vida dessas professoras com o objetivo de saber: Como constituíram sua trajetória de formação docente? Quais diálogos estabeleceram com o grupo de japoneses e o que dessa relação propiciou a incorporação de valores da cultura de origem no seu processo de formação docente? De que forma as marcas da herança cultural consubstanciam a constituição do habitus professoral para ser e estar na profissão?

Diante das interrogações levantadas, realizamos entrevistas de história de vida para reunir memórias das referidas professoras; após transcrevê-las, foi composto o corpus trabalhado com o emprego da técnica de análise de 
conteúdo (Bradin, 2009; Franco, 2008), momento em que utilizamos o software NVivo8 como auxílio tecnológico.

Na sistematização dos dados buscamos uma leitura sociológica amparada no escopo teórico de Pierre Bourdieu e interlocutores. Por meio dela, foi possível analisar as marcas das heranças culturais, explícitas e/ou implícitas, nas narrativas de cada etapa vivida, o que foi explorado a partir de quatro categorias de análise: 1) trajetórias da infância, 2) trajetórias escolares, 3) trajetórias da formação acadêmica/profissional e 4) trajetórias da docência.

A seguir, apresentamos as discussões estruturadas em três tópicos: 1) o estudo do habitus professoral a partir das memórias das professoras aposentadas de origem japonesa; 2) trajetórias de vida e trajetórias de formação docente: marcas da herança cultural nas memórias das professoras; 3) diálogos entre o habitus oriental e professoral revelados nas memórias da docência na escola de cunho étnico Visconde de Cairu.

\section{O ESTUDO DO HABITUS PROFESSORAL NAS MEMÓRIAS DE PROFESSORAS} APOSENTADAS DE ORIGEM JAPONESA

A abrangência de estudos no campo da educação por meio do emprego de abordagens (auto)biográficas, cada vez mais, tem suscitado discussões que consideram os meandros da vida pessoal e profissional como elementos indissociáveis para se pensar a formação e a ação docente, sobretudo "numa profissão fortemente impregnada de valores e de ideais e muito exigente do ponto de vista do empenhamento e da relação humana" (NóvoA, 2007, p. 9).

Nessa perspectiva, realizamos alguns apontamentos teórico-metodológicos sobre a investigação com memórias de professoras aposentadas, de origem japonesa, que lecionaram na já citada escola Visconde de Cairu, criada em 1918.

Trata-se de um estudo educacional que permitiu a interlocução das abordagens: histórica, sociológica e antropológica. Teve por objetivo conhecer o peso da cultura de origem nas trajetórias de formação e ação docente, o que pode ser compreendido a partir da concepção de habitus, conceito

[...] entendido como um sistema de disposições duráveis e transponíveis que, integrando todas as experiências passadas, funciona a cada momento como uma matriz de percepções, de apreciações e de ações - e torna possível a realização de tarefas infinitamente diferenciadas, graças às transferências analógicas de esquemas, que permitem resolver os problemas da mesma forma, e às correções incessantes dos resultados obtidos, dialeticamente produzidas por esses resultados. (BOURDIEU, 1983, p. 65) 
Compreendemos que ser e estar na profissão não se limita aos conhecimentos institucionalizados, isto é, às habilidades e referências educacionais que acionamos como resultado do que foi vivido nas salas de formação docente. Abarca, sim, tudo o que foi experienciado ao longo da vida nas relações com o meio social. É o que esclarecem Passeggi e Barbosa (2008, p. 148): "Não se trata mais de aproximar a educação da vida,'mas de considerar a vida como espaço de educação"'.

Nessa linha, ao tomar conhecimento das trajetórias de vida das professoras, tornou-se possível sublinhar os diálogos estabelecidos por elas com o grupo de pertença, no espaço social de Campo Grande, MS, e, ainda, contar com os diálogos que favoreceram a incorporação de valores, capazes de revestir as maneiras de ser e estar na profissão, isto é, o habitus professoral.

Podemos dizer que o habitus professoral faz parte do conjunto de elementos que estruturam a epistemologia da prática. Trata-se, sobretudo, da estética desse ato, isto é, dos modos de ser e agir de professores e professoras. E essa estética é produzida por meio das influências inexoráveis dos condicionantes advindos da cultura estruturada e estruturante da escola, que subsiste na instituição na qual o sujeito desenvolve sua carreira docente. Outrossim, a produção desse habitus depende da qualidade teórica e cultural da formação dos professores, mas não é desenvolvido durante a formação, e sim durante o exercício profissional. (SILvA, 2005, p. 161)

Assim, dar voz às professoras japonesas aposentadas é considerar o testemunho delas sobre seu passado educacional. É, também, considerá-las como membros do grupo étnico de japoneses que contribuíram expressivamente com a formação social e cultural do município de Campo Grande, MS, cujo cenário pode ser visualizado nas palavras de Brito (1999, p. 42-43):

Esta cidade é formada por diferentes grupos, muitos deles oriundos de outros países, como os japoneses, libaneses, paraguaios, portugueses, dentre outros. Esses grupos de imigrantes, com trajetórias diferenciadas, reelaboram e reinventam suas tradições nesse novo cenário, reconstruindo, assim, o ambiente ancestral impregnado também de características desse novo espaço. [...] metaforicamente, a diversidade cultural da cidade pode ser representada por um caldeirão composto por diferentes ingredientes que ora se misturam ora se separam. (BRITo, 1999, p. 42-43)

Assim, muito se apreende sobre como elas se relacionaram com a sociedade, em suas travessias, de forma mais ampla, em relações responsáveis por propiciar concepções de mundo importantes para o revestimento de suas práticas profissionais. 
Essas biografias, que trazem à tona aspectos da memória do grupo étnico de japoneses em Campo Grande, também expressam as contribuições realizadas pelas professoras no campo da história da educação local, uma vez que atuaram profissionalmente na escola criada para o atendimento do próprio grupo.

Tais colocações evidenciam que não nos constituímos de forma solitária. Ao contrário disso, estamos imersos em um mundo cuja interação possibilita ver, ouvir e realizar práticas traduzidas em percepções, classificações e gostos, em conformidade com os valores sociais incorporados ao longo da vida.

O estudo do habitus professoral favorece apreender "o processo da interiorização da exterioridade e de exteriorização da interioridade" (NoGUEIRA; NogueIRA, 2006, p. 26). Ou, ainda, como destacou Bueno (2006), todo habitus tem uma memória à qual o professor recorre no momento em que sua prática necessita de habilidades e referências para exercer o ensino. Para Bueno (2006, p. 230),

[...] os habitus são disposições incorporadas ao longo da vida do indivíduo, no contato e por meio das relações que cada um desenvolve em seu meio social desde o nascimento. Como bem ressalta Perrenoud (1998), o habitus social constitui a gramática geradora das nossas práticas, ou seja, nossas ações possuem uma memória. Assim, é importante formar o habitus e, no caso dos professores, tanto mais porque uma parte da ação pedagógica é marcada pela urgência e improvisação, por meio da intuição, e é o habitus que permite que os saberes sejam mobilizados no momento necessário.

Examinar a memória das professoras implica considerar que mesmo as lembranças aparentemente expressas como individuais nada mais são do que as expressões coletivas. Isso porque "atribuímos a nós mesmos, como se elas não tivessem sua origem em parte alguma senão em nós, ideias e reflexões, ou sentimentos e paixões, que nos foram inspiradas por nosso grupo" (HALBWACHS, 1990, p. 47).

Nas memórias das referidas docentes, traços de pertença e vínculos com o grupo de japoneses podem se manifestar suplantados por uma ação seletiva. Segundo as colocações de Jedlowsky (2003, p. 217), a memória opera como "uma rede complexa de atividades, cujo estudo mostra que o passado nunca permanece tal e qual, mas é sempre selecionado, filtrado e reestruturado pelas interrogações e pelas necessidades do presente, tanto no nível individual quanto no nível social".

Como se trata aqui de professoras aposentadas, é importante ressaltar que suas memórias diferenciam-se das que atuam na profissão. As 
aposentadas já atravessaram épocas e passaram as várias etapas de uma vida, o que lhes permite recordar os momentos vivenciados com um pano de fundo mais elaborado, portanto, de modo diferente daquele que se observa nas que ainda se encontram envolvidas com os conflitos do trabalho.

Ao estudar um grupo de agentes, como é o caso das professoras em questão, é necessário analisar suas memórias a partir da posição ocupada por esse grupo na complexidade que cerca o espaço social e dos campos em que esses agentes se inseriram. No compartilhamento de um mesmo habitus, as ações provocadas por esse habitus podem elucidar as estratégias de grupo, como aqui é o caso dos japoneses.

O habitus está no princípio de encadeamento das "ações" que são objetivamente organizadas como estratégias sem ser de modo algum o produto de uma verdadeira intenção estratégica (o que suporia, por exemplo, que elas fossem apreendidas como estratégias entre outras possíveis). (BouRDIEU, 1983, p. 61)

As histórias das professoras trazem à tona não apenas as práticas pedagógicas desenvolvidas no campo educacional. Elas revelam práticas que estreitaram vínculos com as estratégias elaboradas pelo grupo de japoneses nesse campo. São aspectos que Demartini (2006) mencionou em seu estudo com professoras de diferentes origens étnicas, que lecionaram em escolas japonesas de São Paulo, conforme se evidencia no trecho a seguir:

As histórias dessas mulheres que foram durante anos professoras de escolas para a população de origem japonesa permitem visualizar como, em seu caminhar, foram, enquanto educadoras, formando novas gerações como elas, na intersecção das culturas oriental e ocidental, em grande parte tão distintas. (DEMARTINI, 2006, p. 290-291)

Há outras pistas que levam a acreditar na relevância de ouvir as professoras, quando, ao longo da existência da escola Visconde de Cairu, sabese que sua criação simbolizou a preocupação dos japoneses em promover oportunidades de acesso ao saber institucionalizado. Havia, também, estratégias do grupo para inserção e ascensão na sociedade de acolhimento e para inculcação de valores da cultura de origem nas gerações de japoneses, de acordo com as discussões levantadas por Brito (2000) e Demartini (1996, 1997, 2000, 2002).

De posse de tais discussões, cabe salientar que, ao longo da existência da referida escola, o professor se tornou um agente que operou práticas educativas em sintonia com os ideais coletivos. Ele estruturou e reestruturou estratégias para a conservação do campo e ofereceu um suporte para os 
descendentes de japoneses, em face das novas necessidades do grupo na sociedade de acolhimento.

Fica claro o processo pelo qual os valores culturais passaram pelas gerações, de modo a favorecer a encarnação das heranças culturais. Embora cada qual possa reinterpretar os valores da cultura de forma diferenciada, ainda assim esses valores são compartilhados como um patrimônio cultural. São solidários aos membros do grupo, cujas representações sociais se relacionam ao passado - guardado e socializado por ele - especificamente, no campo educacional.

Em síntese, o estudo com essas agentes educacionais, mediante aspectos de sua trajetória que mostram as contribuições do grupo para a história da educação e da cidade de Campo Grande, MS, confirma as palavras de Demartini (2006, p. 291), sobre outra pesquisa similar: "Acreditamos que as experiências destas mulheres nos permitem problematizar as questões da educação escolar e das políticas educacionais voltadas para grupos de imigrantes [...]".

TRAJETÓRIAS DE VIDA E FORMAÇÃO DOCENTE: MARCAS DA HERANÇA CULTURAL NAS MEMÓRIAS DE PROFESSORAS

No corpo da professora residem experiências da menina, da estudante, da mulher e das diversas identidades que foram sendo construídas nas trajetórias de formação. [...]. A força desse passado no corpo da professora disponibiliza habitus, que são registros posturais e memória viva dos acontecimentos sociais.

(NASCIMENTO, 2007, p. 28)

Uma vez expostos os caminhos teórico-metodológicos que sustentaram a presente investigação, as discussões levantadas são apresentadas neste tópico a partir das análises das trajetórias de vida das quatro professoras. No decorrer do trabalho, a seguinte pergunta nuclear mobilizou as análises das memórias: como se constituíram e quais elementos da cultura de origem colaboraram nas trajetórias de formação docente?

Assim como Nascimento (2007) chamou atenção nas palavras da epígrafe acima, cada etapa da vida das professoras traz traços da socialização e, por sua vez, essa socialização revela o processo em que valores sociais foram incorporados. Percebe-se, portanto, a dialética estabelecida entre o agente e o meio social.

Assim, quatro etapas da vida das professoras foram examinadas e receberam a denominação de categorias de análise. Elas estão divididas em: 1) trajetórias da infância; 2) trajetórias escolares; 3) trajetórias da formação 
acadêmica/profissional; 4) aposentadoria. Para elucidar, os dados dessas categorias são discutidos na sequência os procedimentos da análise de conteúdo.

Em primeiro lugar, apresenta-se a quantificação dos temas (\%), de acordo com os assuntos narrados pelas professoras. Mediante essa observação, nota-se que para as professoras foi importante explicitar, com maior frequência, as recordações escolares e as da docência. As memórias da formação acadêmica/profissional e da aposentadoria revelaram menos atenção das entrevistadas.

Tabela 1: Quantificação dos temas de acordo com a narrativa das professoras:

\begin{tabular}{|l|c|c|c|c|}
\hline \multicolumn{1}{|c|}{ Temas } & Profa. 1 & Profa. 2 & Profa. 3 & Profa. 4 \\
\hline Memórias da infância/familiares & $10,77 \%$ & $36,04 \%$ & $22,33 \%$ & $13,60 \%$ \\
\hline Memórias escolares & $10,16 \%$ & $4,71 \%$ & $26,09 \%$ & $17,02 \%$ \\
\hline $\begin{array}{l}\text { Memórias da formação acadêmica/ } \\
\text { profissional }\end{array}$ & $12,01 \%$ & $1,62 \%$ & $5,35 \%$ & $5,33 \%$ \\
\hline Memórias da docência & $58,03 \%$ & $42,18 \%$ & $21,85 \%$ & $48,51 \%$ \\
\hline Aposentadoria & $6,71 \%$ & 15,30 & $24,27 \%$ & $15,52 \%$ \\
\hline Total de codificação do texto & $97,68 \%$ & $92,85 \%$ & $97,99 \%$ & $99,98 \%$ \\
\hline
\end{tabular}

Fonte: Dados obtidos no Nvivo8.

No tocante às trajetórias da infância, sete principais assuntos compuseram as narrativas. São eles: 1) histórico e caracterização familiar (32,04\%); 2$)$ vivências e valores familiares $(24,58 \%)$; 3 ) família e grupo étnico de japoneses $(13,30 \%)$; 4) família e escolarização $(10,99 \%) ; 5)$ brincadeiras $(1,41 \%) ; 6)$ práticas culturais e herança cultural na família $(1,27 \%)$; e 7$)$ amizades $(0,31 \%)$.

O inventário desse conteúdo revelou que a família teve peso preponderante na vida das professoras para a manutenção da cultura de origem, ao dispor de elementos para sua inculcação nas gerações seguintes. Os laços de convivência familiar foram estabelecidos com membros imigrantes o que favoreceu amizades com membros do grupo étnico e fomentou práticas como a língua, costumes, hábitos, frequência às festividades japonesas e crenças orientais.

No âmbito familiar, os ensinamentos e as orientações atribuídas às professoras colaboraram com a incorporação de um espírito nipônico desde a infância transmitidos aos descendentes. Entre eles, estão o autocontrole das emoções e o fomento à autodisciplina para alcançar o equilíbrio individual, familiar e a harmonia coletiva. Segundo afirmação de Benedict (1997), esses aspectos são elementos que regularam a vida dos japoneses no passado. 
No caso das quatro professoras, foi possível observar que o valor conferido à educação formal pelas famílias resultou em estratégias para preparar as filhas. Havia o cuidado com sua educação, antes mesmo de elas frequentarem a escola, e o esforço em instituir disciplina no que se refere aos estudos ou na escolha de uma boa escola como investimento familiar.

O que foi subtraído das trajetórias da infância das professoras foi o fato de terem mantido um contato maior com membros do grupo de japoneses (membros familiares ou outros japoneses). Foi isso que possibilitou estreitar o sentimento de pertença ao grupo e a incorporação de valores. Para Bourdieu (1996, p. 125), "concebe-se na família, como uma realidade que transcende seus membros, uma personagem transpessoal dotada de uma vida e de um espírito coletivos e de uma visão específica do mundo."

O que se pretende frisar é que nas famílias das professoras existiu um forte desejo de transmitir os valores culturais japoneses. Houve a disponibilização de elementos para a encarnação de um habitus oriental (DEMARTINI, 1999), capaz de estabelecer laços fortes de união entre os membros familiares e a unicidade de grupo.

O habitus oriental incorporado, em muitas ocasiões [é] difícil de explicar. Pela tradição do povo japonês, não se aprende pelo que é dito, mas pela imitação do outro; difícil portanto explicar o que não se sabe ao certo o que é, sente-se, percebe-se, mas não se consegue explicitar pelas palavras. (DEMARTINI, 1999, p. 12)

Esse habitus oriental, consumido como bem simbólico entre os membros, colaborou com o estabelecimento de fronteiras entre "nós" e os "outros" e com a consolidação de um reduto de valores duradouros nos quais seus membros sempre encontrariam respaldo.

Já no período escolar, receberam destaque a inserção dessas crianças em um universo de novas descobertas, a aquisição de conhecimento e, também, a elaboração de referências educacionais. O conteúdo exposto mostrou que os assuntos "escolarização primária" (22,40\%), "escolarização ginasial" (20,52\%), "estudo" (9,60\%), "professores e diretores" (36,46\%), e "colegas" (4,49\%) nortearam a narração.

Nas trajetórias da escolarização, a frequência às festividades japonesas e o contato com membros do grupo, na escolarização primária de três professoras que estudaram na escola Visconde de Cairu, constituíram-se como uma espécie de extensão de suas casas. Em contrapartida, esse campo educacional não deixou de absorver os valores imbricados na sociedade mais ampla que regulavam o processo educacional em todas as escolas, como afirmou o relato de uma única professora que estudou em escola pública. 
As marcas da política nacionalista (período getulista) engendraram o funcionamento das escolas que desenvolviam práticas de culto ao civismo e aos heróis da pátria, traduzidas em rotinas como: cantar o hino nacional, participar de desfiles cívicos, manter a ordem e a disciplina no âmbito escolar. São valores que foram incorporados como modelos educacionais a serem seguidos por aquelas que mais tarde se tornaram professoras.

Como discutiu Silva (2003), a partir da história da escolarização, a estruturação desses modelos educacionais constitui um campo fecundo para se pensar a formação de professores e as formas pelas quais suas práticas são desempenhadas. Sobretudo porque é na própria experiência como aluno que um professor é capaz de perceber o universo educacional. Sobre esse aspecto, Catani, Bueno e Souza (2000, p. 13) acrescentam:

[...] muitos dos aspectos envolvidos nas imagens e representações sobre o professor estão enraizados nas experiências infantis e na cultura do ensino, forjadas, especialmente, no contato e na convivência dos indivíduos com a própria escola. Diferentemente do que se poderia supor, tais experiências não desaparecem da história do sujeito.

Nas trajetórias escolares das professoras, foi possível constatar que os professores considerados mais enérgicos e rigorosos constituíram-se como referências profissionais para elas. Desse modo, as práticas educativas por eles desempenhadas compuseram um modelo a ser seguido por elas, uma vez constatado que "em experiências vividas durante a história de escolarização há vestígios de um habitus professoral" (SILvA, 2003, p. 14).

Por fim, observamos que, durante a escolarização, as professoras continuaram a viver o drama das tentativas de estabelecimento de fronteiras de diferenciação entre "japoneses" e "outros", o que, consequentemente, influenciou as referências educacionais que foram arrastadas durante a formação acadêmica/profissional.

Nas trajetórias acadêmicas/profissionais, assuntos como "escolha profissional" (27,11\%), "formação técnica, profissional, Curso Normal" (28,27\%), "formação acadêmica" (24,33\%), "professores" (10,21\%) e "início da docência" $(9,66 \%)$ predominaram no conteúdo das narrativas das professoras.

As análises revelaram que a opção pelo magistério se ancorou em sua associação com o papel da mulher, valor presente tanto na sociedade mais ampla quanto no grupo étnico de japoneses. De forma espontânea ou como única opção, a escolha da profissão se constituía como oportunidade para a inserção no mercado de trabalho e para a independência financeira; entretanto, sem se desvencilhar das tarefas e funções atribuídas à mulher japonesa, conforme o relato a seguir: 
Eu sempre quis ser professora. Desde criança nas brincadeiras eu era professora (risos). Eu nunca pensei outra coisa na vida a não ser dar aula, não sei se porque, naquela época, você era professora ou era dona de casa, quase não tinha outras profissões. Para a colônia japonesa, depois que a mulher se casasse, ia cuidar da casa. Eu sempre quis trabalhar como professora, falei: "Professora, depois de casada, dava para continuar".

Com relação a esse detalhe, chamou a atenção o fato de que, mesmo após a conclusão do Curso Normal e já empregadas, houve a continuidade da formação acadêmica. São aspectos que sinalizam um habitus oriental incorporado, uma vez que, para o grupo, o capital cultural institucionalizado era símbolo de sucesso escolar e ascensão social.

Nas análises das trajetórias acadêmicas/profissionais, as marcas do habitus oriental perduraram ao longo da vida dessas professoras, o que favoreceu que se reconhecessem como membros do grupo étnico e que estreitassem seus vínculos de pertença. Ao mesmo tempo, possibilitou agregar valores da sociedade de acolhimento por meio dos diálogos com o espaço social.

Em suas travessias, as análises das trajetórias da infância, da escolarização e da formação acadêmica/profissional revelaram a forma como dialogaram com o grupo de pertença e com a sociedade mais ampla. Nesse processo, as professoras trouxeram as marcas dos valores sociais incorporados e, em especial, os valores do grupo de pertença, que se mostraram presentes, confirmando a durabilidade do habitus oriental.

DIÁLOGOS ENTRE O HABITUS ORIENTAL E PROFESSORAL REVELADOS NAS MEMÓRIAS DA DOCÊNCIA NA ESCOLA VISCONDE DE CAIRU

Cada um tem o seu modo próprio de organizar as aulas, de se movimentar na sala, de se dirigir aos alunos, de utilizar os meios pedagógicos, um modo que constitui uma espécie de segunda pele profissional.

(NóvoA, 2007, p. 16; grifo do autor)

As memórias da docência na escola Visconde de Cairu são o foco de análise neste tópico, que discute o papel que a etnicidade jogou na ação docente nessa escola, isto é, as marcas da herança cultural que foram incorporadas e influenciaram as práticas educativas no referido campo educacional, consubstanciando o habitus professoral.

Se o habitus professoral traduz as maneiras de ser e de estar na profissão, torna-se possível concordar com Abdalla (2004, p. 221) quando 
afirma que "são muitos os efeitos da estrutura da escola no jeito de ser dos professores". Esse aspecto, sob o ponto de vista das agentes educacionais, implica examinar os diálogos estabelecidos entre a educação e os valores da cultura de origem, que estão imersos no campo educacional, no caso a escola Visconde de Cairu.

Em Sá Rosa (1990) aprende-se que a história de vida narrada de forma individualizada pelo(a) professor(a) deve ser olhada sob uma perspectiva ampla, com vistas a analisar o processo educacional no âmago da vida social, circunscrita por um pano de fundo histórico que esboça a cultura produzida pelo homem e, inversamente, a cultura que produz o homem, formada em determinado tempo e espaço social.

Do ponto de vista metodológico, procedemos às análises extraindo o conteúdo destacado nas narrativas das professoras, cujo inventário evidenciou os seguintes assuntos: 1) "atividades profissionais" (9,16\%); 2 ) "aspectos da docência" (72,92\%); 3) "relação com os pais de alunos" (5,14\%); 4) "relação com os colegas" (1,70\%); e 5) "relação com a direção" (10,24\%).

Na vida profissional, o trabalho é visto como uma herança do grupo que foi incorporada. No passado se consubstanciava no gambarê, ou seja, no respaldo para trabalhar ao máximo a fim de alcançar ganhos econômicos para o retorno bem sucedido ao Japão. Sobre a questão afirma Brito (2000, p. 30): "Em uma situação de emigração define-se isto por trabalhar ao máximo e economizar ao máximo, isto é, abrir mão de todo tipo de conforto e tranquilidade".

Certamente, não foi no mesmo contexto nem com tais objetivos que as professoras japonesas atribuíram importância ao trabalho e mediaram suas condutas. Foi o espírito nipônico (gambarê), ainda manifestado como uma herança cultural entre as agentes, que possibilitou a percepção do valor simbólico que o trabalho teve e tem para as professoras e para o grupo. Mostrou-se uma via para a conquista da ascensão econômica e social na sociedade mais abrangente.

Além disso, o trabalho se traduz em um símbolo de dignificação humana que exige esforço e resignação. Em suma, é uma via de acesso ao equilíbrio e à harmonia individual e coletiva, capaz de trazer prosperidade, de acordo com abordagem de Demartini $(1999 ; 2002)$ sobre os japoneses e seu campo do trabalho.

Essa herança cultural, transparece como um ethos, no ritmo acelerado que as professoras têm atualmente. É expressa pela vida movimentada que sempre levam, e pelas pequenas falas que reportam ao passado profissional, quando afirmam: "eu queria trabalhar, não queria ficar parada". Em conjunto, 
são itens que desvelam uma hexis corporal pautada no valor conferido ao trabalho.

O uso inicial da noção de ethos se deveu à opção de esclarecer que existem princípios práticos, que são diferentes dos princípios intencionalmente coerentes que compõem a ética. Assim, a ética seria uma moral sistematizada e o ethos um princípio de ação, inconsciente mais seguindo a sua própria lógica. Ou seja, um sentido inconsciente para os agentes que o possuem. Já a hexis é a "externalização postural" do habitus, que são disposições corporais e gestuais, como maneiras de ser do corpo. E esta é apenas uma dimensão do habitus. (NASCIMENTO, 2007, p. 20-21)

Ao narrarem as memórias da docência na escola Visconde de Cairu, as professoras evidenciaram a visão do local, definindo-a como uma instituição que contribuiu para a formação de muitas gerações de japoneses e cujo rigor disciplinar é uma marca do tradicionalismo escolar nesse campo.

Com base nas concepções educacionais das docentes, foi possível observar que o trabalho desenvolvido por elas se enquadrou nos citados moldes disciplinares e, embora não fossem exclusivos da Visconde de Cairu, ainda assim traduziam uma marca para o grupo étnico e para a escola, que se diferenciava das demais instituições educacionais.

A disciplina, a obediência, o esforço e a pontualidade dos alunos em face das atividades pedagógicas e das tarefas escolares foram marcas de uma herança cultural que engendrou formas de pensar a docência. Os elementos imbricados na prática do professor só se apresentavam porque, igualmente, estavam incorporados como habitus professoral, desvelando as concepções educacionais.

Na docência, as professoras expressaram as fronteiras de diferenciação entre japoneses e outros, por meio de valores como a disciplina rigorosa, a busca do bom comportamento e a obediência. É o que revela uma delas:

Antes a escola dificilmente aceitava o que não fosse descendente de japonês, então os pais ajudavam muito nessa parte, de disciplina e de cobrar estudos deles, que obedecesse a professora, que tivesse organização e ordem nos materiais. Os pais ajudavam muito os filhos, agora eu acho que por conta dos pais trabalharem fora, mesmo os pais descendentes de japoneses, não cobram muito! Eu senti nesse meu retorno, principalmente nos últimos anos que eu regi minha sala, eu já senti falta da cooperação dos pais, mesmo que eles fossem japoneses.

As marcas desses valores culturais regulavam a postura profissional, o jeito de conduzir as aulas, as atividades e o relacionamento com pais e 
alunos. O ethos oriental, nem sempre percebido, manifestou-se nas narrativas das docentes.

Eu dava aula para a quarta série e tinha mães que falavam assim: "Adélia é muito rigorosa! Por que exige tanto desse jeito? O aluno tira nota baixa com ela e consegue passar!"; mas por que consegue passar? Porque eu era exigente! (risos). Isso ninguém entendia, dizia: “Por que você exige tanto assim?". Eu dizia: "Ué! O aluno tem que aprender! Se ele não tiver capacidade e vai fazer um concurso, ele não passa!". Os meus alunos passavam, modéstia à parte! Eu tive muitos alunos que vieram atrás de mim: "Professora, eu vou fazer um concurso e eu quero que a senhora me ajuda". Eu dizia: "Traz o programa, vamos dar uma olhada", em um instante eu dava o básico para eles e pronto! Eles passavam.

Quanto à história construída na escola Visconde de Cairu, especificamente, foi constatado que a referida instituição se transformou e atribuiu novos sentidos para sua conservação. Também ficou claro que na gênese é preciso conservar o projeto de vida do grupo étnico e que, para isso, (re) criam-se e (re)estruturam-se constantemente as estratégias coletivas no campo, em face das novas necessidades do grupo que emergem da sociedade mais ampla.

Observamos que a docência, desenvolvida pelas professoras, constitui-se em sintonia com o grupo. Suas práticas profissionais dialogaram com esse campo, favorecendo a (re)posição e (re)significação dos valores da cultura de origem, sobretudo numa escola que favorecia o relacionamento com membros do grupo, além da realização de práticas simbólicas/culturais, tais como as comemorações de datas alusivas à cultura japonesa, como, por exemplo, o aniversário do Imperador.

O estudo da trajetória das professoras mostrou que as marcas da herança cultural japonesa se compuseram em um processo de interação, com campos sociais diversos e em dados recortes temporais da história. Essas heranças, traduzidas no habitus oriental, colaboraram para a estruturação de um habitus professoral, isto é, as marcas culturais delinearam as formas de ser e de estar na profissão.

O campo da etnicidade mostra que as fronteiras étnicas são móveis. O que se aprende na socialização familiar tende a perdurar, mas, como em um jogo, em diferentes partidas há diferentes vencedores.

\section{À GUISA DE CONSIDERAÇÕES FINAIS}

Na trajetória da infância das professoras, a família exerceu papel fundamental na transmissão de valores culturais. Ela apresentou um universo 
cultural favorável aos caminhos a serem seguidos e orientados pela cultura oriental. Houve o favorecimento de amizades com membros do grupo étnico, o fomento de práticas simbólicas como hábitos, crenças e costumes. Além disso, estratégias familiares na escolarização dos descendentes foram observadas nessa etapa da vida.

Nas trajetórias escolares, os membros da família continuaram a interceder, realizando a escolha das escolas, acompanhando e orientando a vida escolar das professoras. A família realizou estratégias com base nos ideais coletivos, ao buscar a melhor escola para as filhas de acordo com suas possibilidades econômicas.

No processo de escolarização, as entrevistadas foram orientadas no sentido de se esforçarem ao máximo, de modo a ter noção de responsabilidade e autodisciplina para cumprir as tarefas e atividades escolares, tanto no âmbito doméstico como no próprio campo educacional. Nos estudos e em todos os momentos da vida, era preciso manifestar o espírito nipônico do gambarê. Esforçar-se ao máximo, passar por resignações, mas sempre perseverar com afinco e disciplina nos estudos, eram ensinamentos que deveriam reger a vida das professoras em quaisquer circunstâncias.

Durante o novo mundo vivido na escola, elas continuaram a fortalecer os valores coletivos. $\mathrm{Na}$ escola étnica elas continuaram a participar de festividades e comemorações japonesas estabelecendo fronteiras invisíveis de pertença ao grupo. Nas vivências na escola pública, elas fomentaram os valores de grupo ao encontrar respaldo nos valores sociais, inflados pelas políticas nacionalistas de ordem, disciplina, civismo e trabalho, imbricados no campo educacional.

Na trajetória acadêmica/profissional, as marcas impressas pelo grupo e os valores expressos na sociedade mais abrangente mostraram que a busca pelo magistério se devia ao fato de ser uma profissão bem aceita, tanto pelo grupo étnico, como pela sociedade. Para ambos, era considerado como mecanismo de formação das mulheres japonesas em meio a todas as qualidades que cabiam ao seu papel, e como modo de inserção no mercado de trabalho.

Na docência, as marcas culturais ficaram expressas, sobretudo, ao lecionarem em uma escola predisposta a fomentar os valores da cultura de origem e a cumprir o projeto de vida coletivo. Nesse campo educacional, elas apreenderam o papel de agente e desenvolveram a ação docente em concordância com os valores do campo. Elas (re)puseram e (re)significaram suas práticas profissionais; portaram-se e agiram com base na dinâmica educacional com a transformação de suas práticas educativas; (re)formularam 
estratégias para continuar conservando o campo e preparando alunos para as novas necessidades da sociedade contemporânea.

Cabe destacar que as análises das memórias desvelaram que a disciplina, o valor hierárquico, a valorização da educação formal e do trabalho, caracterizaram-se como marcas da herança cultural incorporadas como um habitus oriental. Por sua vez, o habitus oriental teve um peso preponderante para o delineamento do habitus professoral.

Na trajetória do grupo étnico de japoneses, foi possível compreender que os valores étnicos são repassados pelas gerações. Entretanto, na incorporação das heranças culturais, cada geração faz sua ressignificação e, igualmente, não deixa de agregar novos elementos, resultado das vivências locais, no contato com os diversos grupos.

Por fim, o estudo com professoras aposentadas de origem japonesa possibilitou observar que as biografias fornecidas por elas oferecem elementos fecundos para a análise do desenho da história educacional em dado tempo e espaço social. Além disso, propõe um olhar para a formação, a profissionalização e o exercício docente a partir das perspectivas histórica, antropológica e sociológica que problematizam as trajetórias de diferentes segmentos sociais que compõem a sociedade brasileira.

\section{DIALOGUES OF TEACHING AND ORIENTAL HABITUS IN THE MEMOIRS OF RETIRED TEACHERS OF JAPANESE ORIGIN}

ABSTRACT: This study examines memoirs of retired teachers of Japanese origin with a view to understanding the role that the culture of a group of ethnic origin played throughout the formation and teaching journey, establishing ways of being and acting in the profession - teaching habitus. In terms of methodology, life story techniques were used to collect reports and analyze contents while data was organized with the technological help of NVivo8 software. Analyses were undertaken using the theory of Pierre Bourdieu and his interlocutors as a background, which enabled us to see that, along the course of life, teachers incorporated values from their culture of origin, that is, an oriental habitus which lasted and helped in the formation of a teaching habitus.

KEY WORDS: Memoirs. Retired teachers. Oriental habitus. Teaching habitus.

DIÁLOGOS DEL HABITUS PROFESORAL Y ORIENTAL EN LAS MEMORIAS DE PROFESORAS JUBILADAS DE ORIGEN JAPONÉS

RESUMEN: En este trabajo examinamos las memorias de profesoras jubiladas de origen nipón, para comprender el papel que jugó la cultura de su grupo de origen étnico 
en la trayectoria de su formación y acción docente, instituyendo maneras de ser y estar dentro de la profesión - habitus profesoral. Metodológicamente, utilizamos las técnicas de historia de vida para la recolección de los relatos y el análisis del contenido, con el auxilio tecnológico del software NVivo8 para la organización de los datos. Los análisis se hicieron a la luz de la teoría de Pierre Bourdieu y de interlocutores, la cual nos ofreció la posibilidad de constatar que, en las trayectorias de vida, las profesoras incorporaron valores de su cultura de origen, o sea, un habitus oriental que perduró y colaboró con la estructuración de un habitus profesoral.

Palabras claves: Memoria. Profesoras jubiladas. Habitus oriental. Habitus profesoral.

\section{NOTAS}

1. Este texto foi apresentado originalmente na 34a Reunião Anual da Associação Nacional de Pós-graduação e Pesquisa em Educação - Anped (2011), no Grupo de Trabalho Formação de Professores.

2. Com base nos estudos de Demartini (1999; 2006), denominamos a escola estudada "escola de cunho étnico" por tratar-se de uma escola fundada por japoneses e para os japoneses, cujos moldes educativos cunharam-se na cultura de origem do grupo étnico.

\section{REFERÊNCIAS}

ABDALLA, M. F. B. Da teoria da ação em Bourdieu para repensar a formação de professores. Educação e Linguagem, São Paulo, n. 10, p. 209-225, jul./dez. 2004.

BARDIN, L. Análise de conteúdo. 4. ed. Tradução de Luis Antero Reto e Augusto Pinheiro. Lisboa: Ediç̧̃̃es 70, 2009.

BENEDICT, R. O crisântemo e a espada. Tradução de César Tozzi. 2. ed. São Paulo: Perspectiva, 1997.

BOURDIEU, P. Esboço de uma teoria da prática. In: ORTIZ, R. (Org.). Pierre Bourdieu. Sociologia. São Paulo: Ática, 1983. p. 46-81.

Razões práticas: sobre a teoria da ação. 9. ed. Tradução de Mariza Corrêa. Campinas, SP: Papirus, 1996.

BRITO, C. A cultura japonesa em Campo Grande. In: FUNCESP. Série Campo Grande, ano I, Campo Grande, MS: Fundação Municipal de Cultura Esporte e Lazer; ARCA, p. 41-47, 1999.

Escola de japoneses. A construção da etnicidade em Mato Grosso do Sul. Campo Grande, MS: UNIDERP, 2000. 
BUENO, B. O. É possível reiventar os professores? A "escrita de memórias" em um curso especial de formação de professores. In: SOUZA, E. C.; ABRAHÃO, M. H. M. B. (Org.). Tempos, narrativas e ficções: a invenção de si. Porto Alegre: EDIPUCRS, 2006. p. 219- 238.

CATANI, D. C.; BUENO, B. A. O.; SOUZA, C. P. O amor dos começos: por uma história das relações com a escola. Cadernos de Pesquisa, São Paulo, n. 111, p. 151-171, 2000.

DEMARTINI, Z. B. F. Viagens vividas, viagens sonhadas: os japoneses em São Paulo na primeira metade deste século. São Paulo: CERU, n. 7, p. 77-95, 1997.

Vivências diferenciadas entre três gerações de japoneses em São Paulo. Travessia, São Paulo, n. 35, p. 10-16, set./dez. 1999.

. Relatos orais de famílias de imigrantes japoneses: elementos para a história da educação brasileira. Educação e Sociedade, São Paulo, n. 72, v. 21, ago. 2000. Disponível em: <http://www.scielo.br/pdf/es/v21n72/4193.pdf>. Acesso em: dez. 2010.

. Diferentes gerações de imigrantes e educação: uma opção metodológica. São Paulo: CERU, n. 9, p. 133-151, 2002.

. Memórias que interrogam: formação e atuação docente. In: SOUZA, E. C.; ABRAHÃO, M. H. M. B. (Org.). Tempos, narrativas e ficções. Porto Alegre: EDIPUCRS, 2006. p. 279-295.

FRANCO, M. L. P. B. Análise de conteúdo. 3. ed. Brasília: Líber Livro, 2008. (Série Pesquisa, v. 6).

HALBWACHS, M. A memória coletiva. 2. ed. Tradução de Laurent Leon Schaffter. São Paulo: Vértice, 1990.

JEDLOWSKI, P. Memória: temas e problemas da sociologia da memória no século XX. Pro-posições. Campinas, SP, n. 1, p. 217-233, jan./abr. 2003.

NASCIMENTO, M. A. Os habitus professorais: a prática pedagógica em diferentes lugares - ocasiões. Dissertação (Mestrado em Educação) - Universidade do Estado do Rio de Janeiro, Rio de Janeiro, 2007.

NOGUEIRA, M. A; NOGUEIRA, C. M. M. Bourdieu e educação. Belo Horizonte: Autêntica, 2006.

NÓVOA, A. Os professores e as histórias de sua vida. In: NÓVOA, A. (Org.). Vidas de professores. Portugal: Porto, 2007. p. 11-27.

PASSEGUI; M. C.; BARBOSA, T. M. N. A (re)invenção de si na formação docente. SOUZA, E. C.; MIGNTOT, A. C. V. (Org.). Histórias de vida e formação de professores. Rio de Janeiro: Quartet/FAPERJ, 2008. p. 147-167.

SÁ ROSA, M. G. Memória da cultura e da educação em Mato Grosso do Sul. Campo Grande, MS: UFMS, 1990. 
SILVA, M. O habitus professoral: o objeto dos estudos sobre o ato de ensinar na sala de aula. Revista Brasileira de Educação, Rio de Janeiro, n. 29, p. 152-164, maio./jun./ jul./ago. 2005.

. Como se ensina e como se aprende a ser professor. Bauru, SP: EDUSC, 2003.

Miriam Mity Nishimoto possui mestrado em Educação (UFMS/ 2011), especialização em Planejamento e Tutoria em EAD (UFMS/ 2009) e graduação em Pedagogia (UFMS/2006). Atualmente atua como coordenadora de tutores do curso de Pedagogia UAB/UFMS, é membro do Grupo de Estudos e Pesquisas em Antropologia e Sociologia da Educação (GEPASE/UFMS), membro do Centro de Análise e Difusão do Espaço Fronteiriço (CADEF/UFMS) e bolsista IPEA no projeto de pesquisa: Mercosul e regiões de fronteira (SEMAC/IPEA). E-mail: miriamity@hotmail.com

Jacira Helena do Valle Pereira possui graduação em Pedagogia pela Universidade Federal de Mato Grosso do Sul (1988), mestrado em Educação pela Universidade Federal de Mato Grosso do Sul (1997) e doutorado em Educação pela Universidade de São Paulo (2002). Atualmente é professora associada da Universidade Federal de Mato Grosso do Sul. Tem experiência na área de Educação, com ênfase em Sociologia da Educação, atuando principalmente nos seguintes temas: memória e memorialistas, fronteira e diversidade cultural, famílias e escolas.

E-mail: jpereira.dou@terra.com 